\title{
The Effects of Ascorbic Acid and U-74389G on Renal Ischemia-Reperfusion Injury in a Rat Model
}

\author{
CONSTANTINOS G. ZOGRAFOS ${ }^{1,2^{*}}$, DIMOSTHENIS CHRYSIKOS ${ }^{1,2^{*}}$, THEODOROS PITTARAS ${ }^{1,3}$, \\ VASILEIOS KARAMPELIAS ${ }^{4}$, AIKATERINI CHAIRAKAKIS ${ }^{1}$, ANTONIS GALANOS ${ }^{1}$, \\ IOANNIS SFINIADAKIS ${ }^{5}$, EVANGELOS FELEKOURAS ${ }^{6}$, GEORGE C. ZOGRAFOS ${ }^{2}$, \\ MICHAIL SIDERIS ${ }^{7}$, KONSTANTINA PAPADOPOULOU ${ }^{1}$ and APOSTOLOS E. PAPALOIS ${ }^{1,8}$ \\ ${ }^{1}$ Experimental, Educational and Research Center ELPEN, Athens, Greece; \\ ${ }^{2} 1^{\text {st }}$ Department of Propaedeutic Surgery, Hippokration Hospital, Athens, Greece; \\ ${ }^{3}$ Hematology Laboratory - Blood Bank, National and Kapodistrian University \\ of Athens School of Medicine, Aretaieion Hospital, Athens, Greece; \\ ${ }^{4}$ School of Medicine, University of Patras, Patras, Greece; \\ ${ }^{5}$ Pathology Laboratory, Athens Naval Hospital, Athens, Greece; \\ ${ }^{6}$ First Department of Surgery, Laikon General Hospital, \\ National and Kapodistrian University of Athens, Athens, Greece; \\ ${ }^{7}$ Barts and the London School of Medicine and Dentistry, \\ Queen Mary University of London, London, U.K.; \\ ${ }^{8}$ School of Medicine, European University Cyprus, Nicosia, Cyprus
}

\begin{abstract}
Background/Aim: $U-74389 G$ and ascorbic acid protect the cells from oxidation. This study aimed to depict their role in ischemia-reperfusion injury in a renal rat model. Materials and Methods: Sixty Wistars rats were randomized into six groups of 10 animals each. Group A Ischemia $30 \mathrm{~min}$, reperfusion $60 \mathrm{~min}$; Group B Ischemia $30 \mathrm{~min}$, reperfusion 120 min; Group C Ischemia $30 \mathrm{~min}$, ascorbic acid administration, reperfusion $60 \mathrm{~min}$; Group D Ischemia $30 \mathrm{~min}$, ascorbic acid administration, reperfusion $120 \mathrm{~min}$; Group E Ischemia $30 \mathrm{~min}$, $U-74389 G$ administration, reperfusion $60 \mathrm{~min}$; Group $F$ Ischemia $30 \mathrm{~min}, U-74389 \mathrm{G}$ administration, reperfusion 120 min. We then collected tissue and blood samples. Results: Histology and the significantly decreased malondialdehyde and tumor necrosis factor- $\alpha$ levels indicated that ascorbic acid was superior to U-74389G, at pre-defined time intervals. Conclusion: Ascorbic acid and U-74389G ameliorated renal damage induced by ischemia-reperfusion injury, suggesting a therapeutic effect.
\end{abstract}

This article is freely accessible online.

*These Authors contributed equally to this study.

Correspondence to: Apostolos E. Papalois, Ph.D., KGSJ, AMACS, 95 Marathonos Avenue, 19009, Pikermi, Athens, Greece. Tel: +30 6977711125, e-mail: apapalois@elpen.gr

Key Words: Antioxidants, ascorbic acid, kidney, reperfusion injury.
Renal ischemia-reperfusion injury (RIRI) is an essential clinical concern. Clinically, it commonly presents as either an embolic or a thrombotic episode related to acutely or chronically established hypotension or as a postoperative complication following cardiac bypass surgery. The most prominent renal damage is related to kidney transplantation that affects shortterm and long-term graft function and patient morbidity and mortality (1). RIRI can cause significant acute kidney damage and tubular cell death either by necrosis or apoptosis (2). The kidneys are strongly predisposed to ischemia. The discrepancy between blood oxygen supply and functional need, results in a decrease in oxidative metabolism, and a progressive damage and death of tubular epithelial cells (3). Consequently, the kidneys lose their homeostatic regulation of metabolic waste products, resulting in water and electrolyte imbalance.

Free oxygen radicals are mainly responsible for RIRI. Studies $(4,5)$ have reported that ischemia and reperfusion generate a systemic inflammatory cascade in various organs (e.g., pancreas, liver, and intestines) by free oxygen radical and cytokine (6-8) production.

To describe and delineate the complexity of the pathogenetic mechanisms in the post-ischemic kidney, many experimental studies have examined the efficacy of different potentially therapeutic agents that could prevent renal damage. Various studies have suggested efficient or inefficient RIRI treatments; most such studies used experimental animal models, and the substances tested remain to be examined by human controlled trials. 
Many of the agents tested were oxygen-free radical scavengers that have a short half-life and are unable to circulate and enter the target cell, e.g. the renal tubular cell (9). Failure may also be due to antioxidants having a relatively high molecular weight and thus, cannot readily enter the renal tubular cells in adequate concentrations.

$\mathrm{U}-74389 \mathrm{G}$ resides in lazaroids that are low molecular weight antioxidants. Lazaroids are synthetized from aminosteroids. They are deprived of glucocorticoids and mineralocorticoids in nature and act by inhibiting irondependent lipid peroxidation. Other potential mechanisms of action include oxygen-free radical-scavenging, ironchelating, and membrane-stabilizing (10-12). Moreover, lazaroids inhibit cytokine release, adhesion molecule expression, and infiltration or activation of neutrophils. Various experimental studies have shown that antioxidants and specific lazaroids attenuate IRI in vital organs (13-23).

Vitamin C (or ascorbic acid) is a water-soluble antioxidant involved in the formation of collagen, the metabolism of carnitine and catecholamine and in dietary iron uptake. Humans cannot synthesize ascorbic acid, and thus it is crucial to include it in their diet. Finally, ascorbic acid is responsible for the hydroxylation of proline residues in procollagen to form mature collagen with a stable triple-helix (24).

Tumor necrosis factor-alpha (TNF- $\alpha$ ) is an inflammatory cytokine. Therapeutic attempts aim to neutralize TNF- $\alpha$ by targeting antibodies or inhibiting the TNF- $\alpha$ receptor. Malondialdehyde (MDA) is an aldehydic lipid hydroperoxide decomposition product synthesized upon oxygen-free radicalinduced damage of cellular lipids. Considering that the lazaroids' mechanism of action is free radical scavenging, we hypothesized that MDA levels could accurately estimate lazaroid's effect in experimental studies, such as those using RIRI models. Moreover, in experimental studies of IRI, U$74389 \mathrm{G}$ decreased TNF- $\alpha$ levels (6-8).

In light of these findings, our study aimed to assess the potential effect of lazaroid U-74389G and ascorbic acid as therapeutic agents following RIRI in a Wistar rat model; several clinicopathological and biochemical parameters, TNF- $\alpha$, and MDA were examined.

To our knowledge, information is lacking regarding the simultaneous administration of U-74389G and ascorbic acid in a common experimental animal model of RIRI.

The deep understanding of the molecular mechanisms involved in RIRI and their impact on long-term kidney function are fundamentally important in for the development of novel therapeutic approaches.

\section{Materials and Methods}

Experimental animals. The Pasteur Institute supplied the laboratory male (3-to-4-month old) Wistar rats. Experiments were performed at the accredited laboratory of the Experimental, Educational and Research Center (ELPEN) in Athens, Greece. All animals were acclimatized in conventional environmental conditions [temperature $\left(22-25^{\circ} \mathrm{C}\right)$, humidity (55\%-58\%) and lighting (12 h light/dark cycles)], with free access to food and water. The experimental procedures strictly conformed to the National Research Council Guide for the Care and Use of Laboratory Animals and the Directive 86/609 of the European Union, protocol number K/2284.

All experiments were approved by ELPEN Laboratories and veterinary authorities of East Attica Region in accordance with the principles of the Helsinki Declaration and Greek Law No. 160, A64, May 1991, European Union regulations.

Study design. Sixty male Wistar rats, weighting 280-350 g, were used in this study. The animals were distributed randomly into the following six experimental groups: Group $A$ (control group, $n=10$ ): 30-min kidney ischemia and 60-min reperfusion, Group B $(n=10)$ : 30-min kidney ischemia and 120-min reperfusion, Group C $(n=10)$ 30 -min kidney ischemia and inferior vena-cava IV ascorbic acid injection $(10 \mathrm{mg} / \mathrm{kg})$, followed by 60 -min reperfusion, Group D $(n=10) 30$-min kidney ischemia, inferior vena-cava IV ascorbic acid injection $(10 \mathrm{mg} / \mathrm{kg})$, followed by 120 -min reperfusion, Group E $(n=10)$ 30-min kidney ischemia, inferior vena-cava IV U-74389G injection $(10 \mathrm{mg} / \mathrm{kg})$, and 60-min reperfusion, Group F ( $\mathrm{n}=10) 30$ min kidney ischemia, inferior vena-cava IV U-74389G injection (10 $\mathrm{mg} / \mathrm{kg}$ ), and 120-min reperfusion. We sampled tissues and blood at 30-min intervals, 0-120 min following reperfusion.

The U-74389G dose was $10 \mathrm{mg} / \mathrm{kg}$ body weight $\left(\right.$ CALBIOCHEM $^{\circledR}$ Company, Cat. No. 153190-29-5, for experimental use). This lazaroid dose has also been used in previous experimental studies from the same laboratory using U-74389G (6-8); this dose has also been used in various other experimental models $(6-8,23)$ and appears to be beneficial. The ascorbic acid dose (VITAMIN-C-LOGES Optipharm Co, 1 ampule $100 \mathrm{mg} / \mathrm{ml}$ ) was also $10 \mathrm{mg} / \mathrm{kg}$ body weight. Before the experiment, the rats were naturalized to the laboratory for 7 days.

Anesthesia protocol and operative technique. Animals were placed in a glass cage where the anesthesia protocol was followed. Anesthesia included isoflurane administration, following a $0.25 \mathrm{ml}(10 \mathrm{mg} / \mathrm{ml})$ subcutaneous injection of the opioid butorphanol as an analgesic (Dolorex; Intervet, Schering-Plough Animal Health, Boxmeer, the Netherlands). After $3 \mathrm{~min}$, the state of anesthesia of the animals was confirmed by lack of swallowing movements, immobility, and loss of the tail flick reflex. Afterward, we placed the animals on the operating table and performed endotracheal intubation (EI) under direct laryngoscopy using a $16 \mathrm{Fr}$ venous catheter. Indeed, rat experiments can also be performed without EI using rat facemasks or ketamine alone; however, EI was the preferred method of controlled mechanical ventilation. EI is proposed by most researchers in their experimental protocols. On the operating table, animals were placed in the supine position; they were immobilized, and their mandible was stabilized. The endotracheal tube and the anesthetic gas tubing were stabilized with adhesive bands

Abdominal hair was shaved, and the skin was disinfected with $10 \%$ iodine povidone. A midline incision was made from the xiphoid process, $3 \mathrm{~cm}$ caudally of the linea alba. The abdominal cavity was then entered, and the kidney was mobilized and freed from its attachments. The renal artery and vein were prepared for complete occlusion with surgical bulldog clips to apply the ischemia-reperfusion protocol. Following U-74389G and ascorbic acid administration via the inferior vena cava, the clips were removed. The abdominal cavity was closed with 2-0 Vicryl sutures and the animals remained anesthetized for 60 or $120 \mathrm{~min}$ (in the 
respective experimental groups). The linea alba was approximated using 3/0 Vicryl sutures and the skin using 3/0 Nylon sutures. The experimental procedure was acute (short-term), and the animals were euthanatized postoperatively. Finally, the tissue samples obtained from the kidneys were evaluated histopathologically.

Histopathological assessment. We fixed the tissue specimens in formalin $(4 \%)$ and embedded them in paraffin. Tissue sample sections in $4 \mu \mathrm{m}$ of paraffin-embedded specimens were deparaffinized, rehydrated, and stained with hematoxylin and eosin according to standard procedures.

The histopathological assessment was based on the grade of the following parameters: Initially, histological grading of necrosis was performed using a scale ranging from $0-3 ; 0=$ no necrosis, $1=$ less than $10 \%$ necrosis per high-power field (HPF), $2=10-20 \%$ necrosis per HPF, $3=$ higher than $20 \%$ necrosis per HPF. Then, grading of degeneration of the renal tubules was performed as follows, $0=$ absent, $1=1-2$ degenerated renal tubules per HPF, 2=2-4 degenerated renal tubules per HPF, $3=$ more than four degenerated renal tubules per HPF.

Two experienced pathologists (TP and IS) examined the specimens independently and in a blinded manner, under a Nikon eclipse 50i microscope.

Biochemical parameters, MDA, and TNF- $\alpha$ Measurements. To evaluate MDA, N-methyl-2-phenylindole (MPI), which is a chromogenic agent, reacted with MDA at $45^{\circ} \mathrm{C}$. The reagents were: MPI reagent, $10.3 \mathrm{mmol} / 1 \mathrm{MPI}$ in acetonitrile, MDA standard, 10 $\mathrm{mmol} / \mathrm{l}$ 1,1,3,3-tetramethoxypropane in $20 \mathrm{mmol} / \mathrm{l}$ Tris- $\mathrm{HCl}, 500$ $\mathrm{mmol} / \mathrm{l}$ butylated-hydroxytoluene in acetonitrile, $20 \mathrm{mmol} / \mathrm{l}$ Tris buffer $\mathrm{pH} 7.4,0.9 \% \mathrm{NaCl}, 37 \%$ (12 mol/l) high-pressure liquid chromatography grade $\mathrm{HCl}$, high-pressure liquid chromatography grade methanol, and acetonitrile. Based on standard practice, one volume of $100 \%$ methanol was diluted with three volumes of the MPI reagent. We rinsed the tissue samples with ice-cold isotonic saline and homogenized them in Tris-buffer $20 \mathrm{mmol} / \mathrm{l} \mathrm{pH} 7.4$ with an Ultra-Turrax (Ika- Labortecnik) blender $(1 \mathrm{ml}$ Tris $/ 0.1 \mathrm{~g}$ of tissue). For sample-oxidation prevention, we added $10 \mathrm{ml}$ butylated hydroxy toluene $(500 \mathrm{mmol} / \mathrm{l})$ to $1 \mathrm{ml}$ tissue homogenate. The homogenate was centrifuged at $3000 \mathrm{rpm}$ with a $10 \mathrm{~cm}$ radius centrifuge that delivered a centrifugal force of $1,006 \times \mathrm{g}$, at $4^{\circ} \mathrm{C}$ for $10 \mathrm{~min}$. Then, $0.2 \mathrm{ml}$ of the supernatant of the tissue homogenate was maintained in a polypropylene microcentrifuge tube, and 0.65 $\mathrm{ml}$ of the diluted MPI reagent was added. We vortexed the mixture and added $0.15 \mathrm{ml}$ of $\mathrm{HCl}(12 \mathrm{~mol} / \mathrm{l})$. We incubated the tubes at $45^{\circ} \mathrm{C}$ for $60 \mathrm{~min}$ and then centrifuged them at $6000 \mathrm{rpm}$ with a 10 $\mathrm{cm}$ radius centrifuge that delivered a centrifugal force of $4,025 \times \mathrm{g}$ for $15 \mathrm{~min}$; $0.8 \mathrm{ml}$ of the supernatant was used to measure MDA at $586 \mathrm{~nm}$. The MDA standard curve was prepared by successive dilutions of the stock tetramethoxypropane solution $(10 \mathrm{mmol})$. The final standard concentrations were $2.08,4.16,8.33,12.5$, and 16.66 $\mu \mathrm{mol} / 1$, and the absorbance values were $0.059,0.124,0.264,0.4$ and 0.545 , respectively $(6-8,13)$.

We measured TNF- $\alpha$ using an enzyme-linked immunosorbent assay in tissue homogenate. A swine, not a human, anti-TNF- $\alpha$ antibody was used (anti-swine; BIO SOURCE Co., Carlsbad, CA, USA) (13) to avoid cross reactions that may interfere with the results.

Further, we measured the complete blood cell count and serum biochemical parameters (i.e., sodium, potassium, glucose, creatinine, urea, SGOT/AST, SGPT/ALT, gamma-GT, total bilirubin, direct bilirubin levels) at $30 \mathrm{~min}$ intervals (0-120 min) after reperfusion (13).
Table I. Pathology results.

Group A Group B Group C Group D Group E Group F

\begin{tabular}{|c|c|c|c|c|c|c|}
\hline $\begin{array}{l}\text { Necrosis } \\
\text { score } \\
(0,1,2,3)\end{array}$ & 2.6 & 2.7 & 1.4 & 1.7 & 1.1 & 1.5 \\
\hline $\begin{array}{l}\text { Degeneration } \\
\text { renal } \\
\text { tubules } \\
\text { score } \\
(0,1,2,3)\end{array}$ & 2.7 & 3 & 1 & 1 & 1 & 1 \\
\hline
\end{tabular}

Statistical analysis. Data are expressed as mean \pm standard deviation (SD) for continuous variables and as percentages for categorical variables. We used the Shapiro-Wilk test to measure the normal distribution of the variables.

Comparison of variables between the three intervention groups (control vs. U-74389G vs. ascorbic acid) was performed using oneway analysis of variance followed by post-hoc comparisons using the Bonferroni test. Kruskal-Wallis and Mann-Whitney tests were used for non-parametric analyses as needed.

Comparison of the variables between the two reperfusion times (60 min vs. $120 \mathrm{~min}$ ) per intervention group was performed using the $t$-test or Mann-Whitney test (in case of violation of normality).

All tests were two-sided. A $p<0.05$ was considered significant. All analyses were performed using SPSS version 21 (IBM Corp., Armonk, NY, USA).

\section{Results}

Pathology results. The pathology score analysis revealed a statistically significant difference $(p=0.007)$ regarding necrosis and degeneration of renal tubules. Comparative analysis revealed a statistically significant difference between group A (necrosis score 2.6/degeneration of renal tubules score 2.7) and group B (necrosis score 2.7/degeneration of renal tubules score 3$)(p=0.013)$ and $\mathrm{C}$ (necrosis score 1.4/degeneration of renal tubules score 1 ) $(p=0.022)$ (Table I, and Figures 1 and 2).

A statistically significant difference was observed in the pathology score $(p=0.007)$ among groups $\mathrm{D}$ (necrosis score $1.7 /$ degeneration of renal tubules score 1 ), E (necrosis score 1.1/degeneration of renal tubules score 1) (Figures 3 and 4) and $\mathrm{F}$ (necrosis score 1.5/degeneration of renal tubules score 1) (Figure 5). The multiple comparisons showed a difference between group D and groups $\mathrm{E}(p=0.013)$ (Figures 6 and 7) and $\mathrm{F}(p=0.022)$ (Table I), (Figure 8).

MDA and TNF- $\alpha$ per group results. There was no significant difference among groups $\mathrm{A}, \mathrm{B}$, and $\mathrm{C}$ regarding MDA- $\mu \mathrm{M}$ and TNF- $\alpha \quad(p=0.678)$. Conversely, we noted a statistically significant difference among groups $\mathrm{D}, \mathrm{E}$, and $\mathrm{F}$ for MDA- $\mu \mathrm{M}$ $(p=0.010)$ and TNF- $\alpha(p=0.0005)$ (Figure 3$)$. 


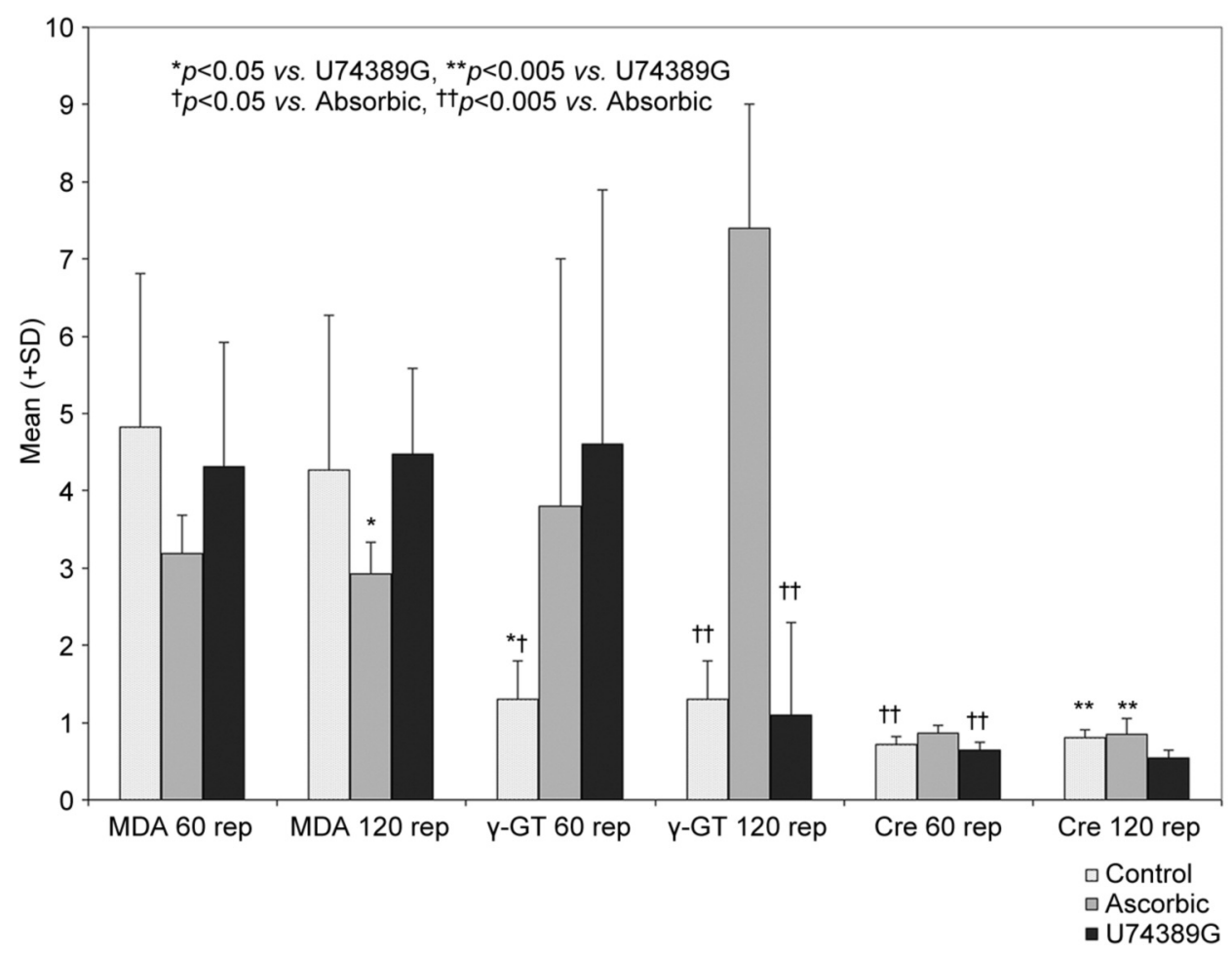

Figure 1. Main variables among the groups expressed as MEAN+SD after 60 min and 120 min of reperfusion.

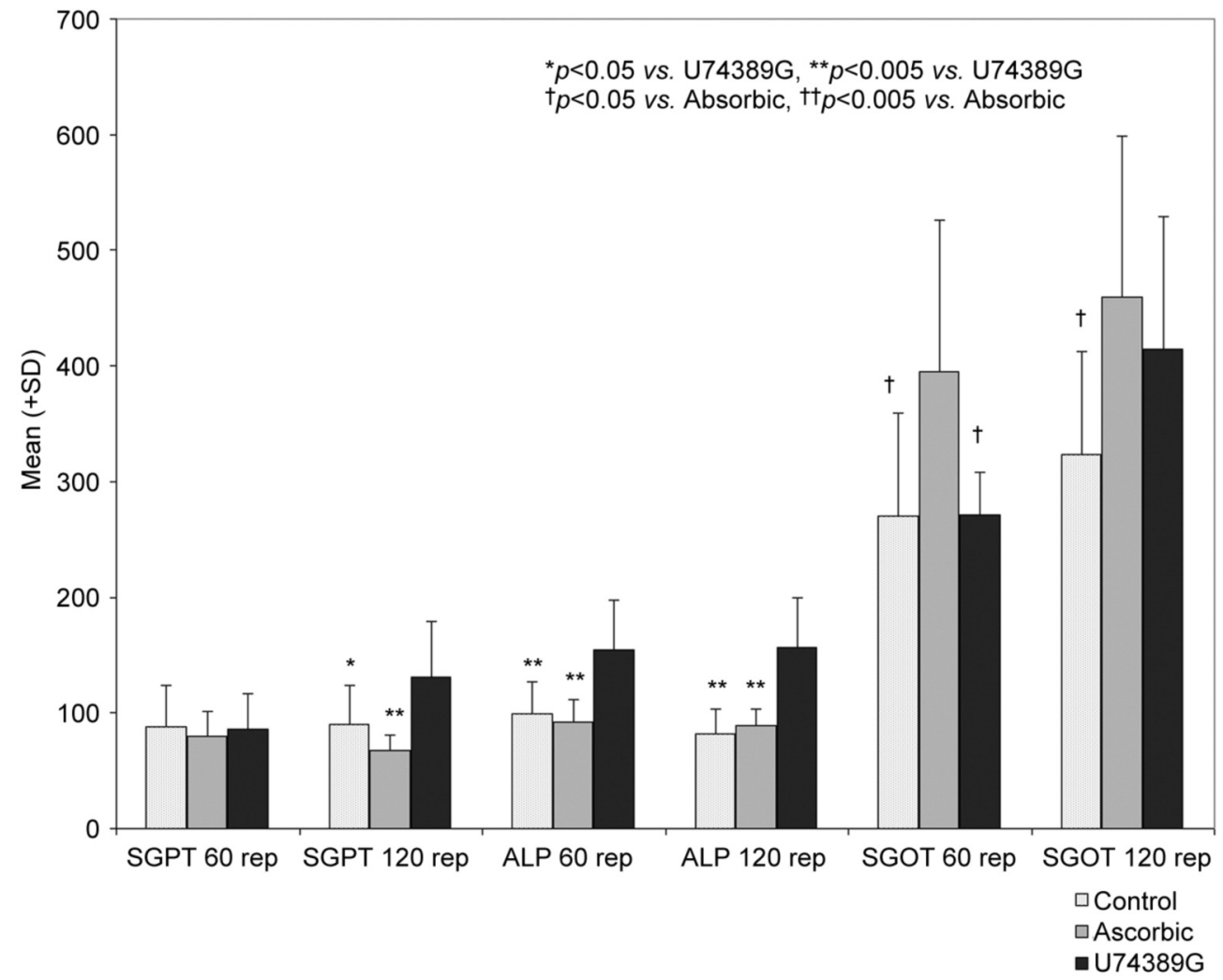

Figure 2. Main variables among the groups expressed as MEAN+SD after 60 min and 120 min of reperfusion. 


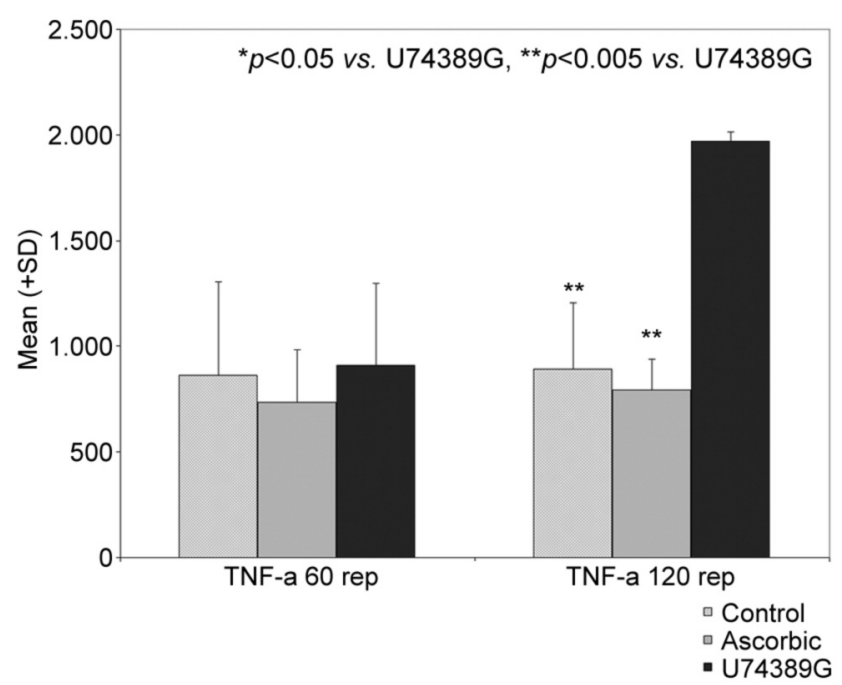

Figure 3. No statistically significant difference in TNF- $\alpha$ between the compared groups at 60 min reperfusion. $U-74389 G$ group presents statistically significantly higher values of TNF- $\alpha$ compared to the ascorbic acid group $(p=0.049)$ at 120 min reperfusion.

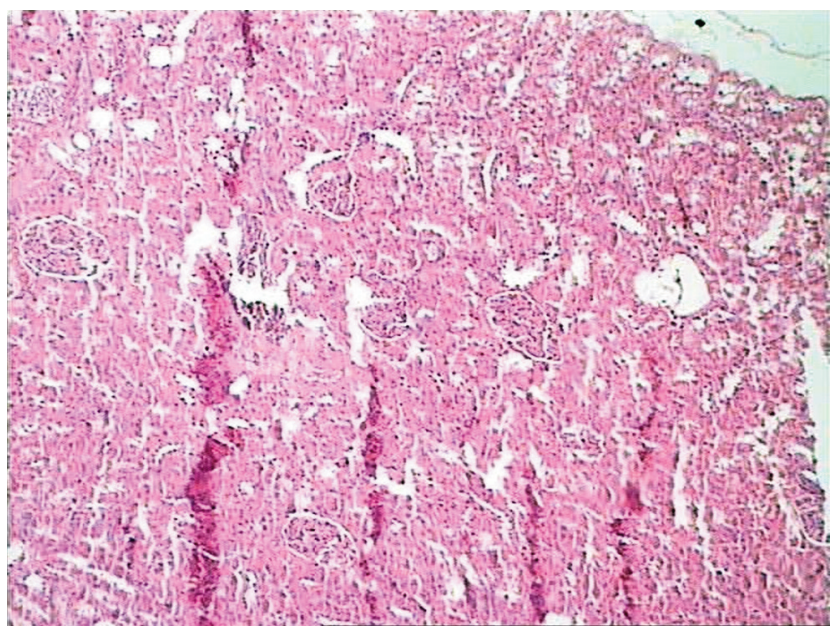

Figure 4. Vascular dilatation and congestion with areas of necrosis (250x). Group C (kindly ischemia (30 min), ascorbic acid administration, followed by reperfusion for $60 \mathrm{~min}$ ).

Results at $60 \mathrm{~min}$ reperfusion. No statistically significant difference was observed among the groups for MDA $(\mu \mathrm{M})$ $(p=0.085)$, TNF- $\alpha(p=0.546)$, and SGPT $(p=0.820)$. The ALP values were significantly higher in the U74389G group than in the control $(p=0.002)$ and ascorbic-acid $(p<0.001)$ groups. The $\gamma$-GT values were significantly lower in the control group than in the ascorbic acid $(p=0.051)$ and $\mathrm{U} 74389 \mathrm{G}$ $(p=0.231)$ groups (Figures 1 and 2). The ascorbic-acid group had statistically significant higher values of SGOT than the control $(p=0.002)$ and U74389G $(p<0.001)$ groups (Table II).

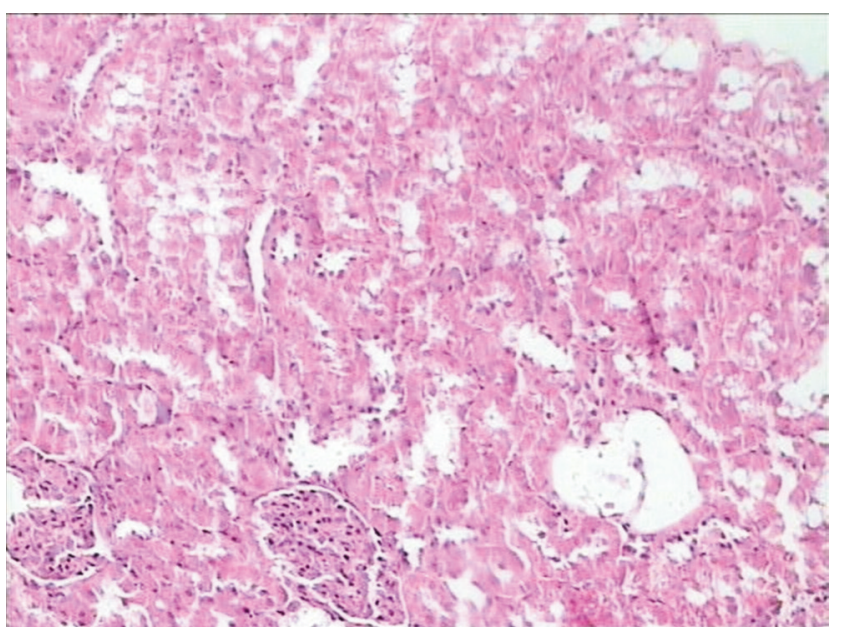

Figure 5. Vascular dilatation and congestion with areas of necrosis (400x). Group C [kidney ischemia (30 min), ascorbic acid administration, followed by reperfusion for $60 \mathrm{~min}]$.

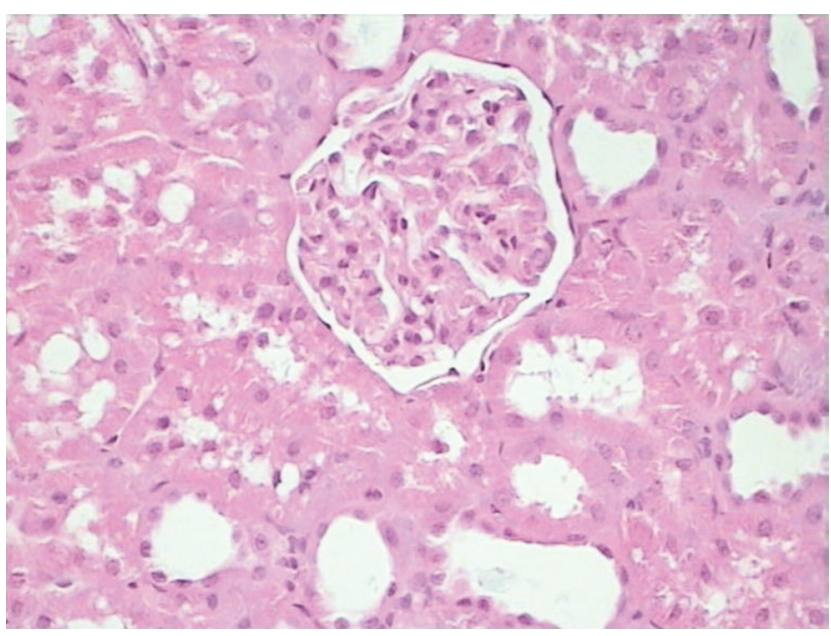

Figure 6. Normal tubular architecture of the kidney (400x). Group E (kidney ischemia (30 min), U-74389G intravenous injection, and reperfusion for $60 \mathrm{~min}$ ).

Results at 120 min reperfusion. The TNF- $\alpha$ values were significantly higher in the U74389G group than in the control $(p<0.001)$ and ascorbic acid $(p<0.001)$ groups. The SGPT values were significantly higher in the U74389G group than in the control $(p=0.046)$ and ascorbic acid $(p=0.001)$ groups. The ALP values were significantly higher in the U74389G group than in the control $(p<0.001)$ and ascorbic acid $(p<0.001)$ groups. The creatinine values were significantly higher in the U74389G group than in the control $(p=0.004)$ and ascorbic acid $(p=0.001)$ groups. The 


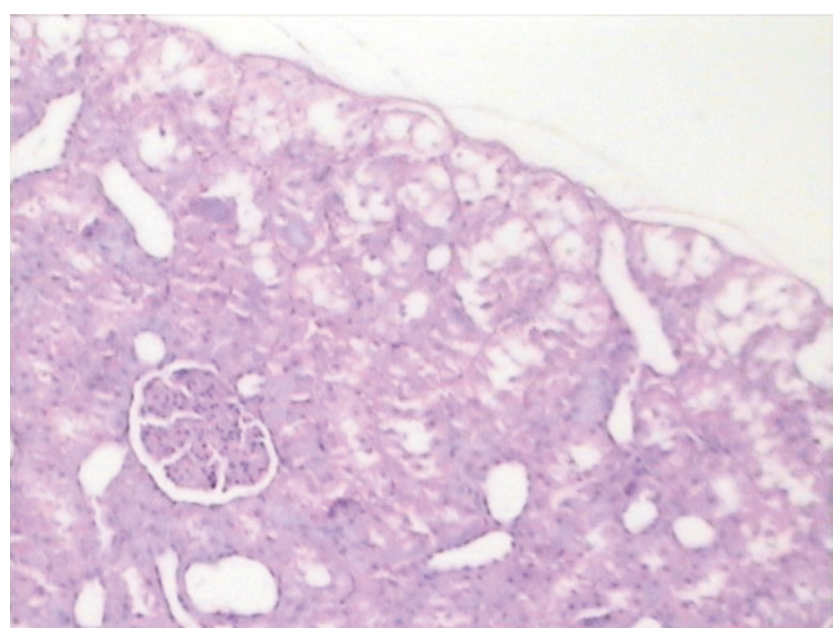

Figure 7. Isolated degenerated renal tubules mainly peripherally. Group E [kidney ischemia (30 min), U-74389G intravenous injection, and reperfusion for $60 \mathrm{~min}]$.

TNF- $\alpha$, SGPT, ALP, values were significantly higher in the U74389G group than in the control $(p<0.01)$ and ascorbic acid $(p<0.01)$ groups. The TNF- $\alpha$ value was significantly higher in the U74389G group than in the ascorbic acid group $(p=0.049)$ (Figures 1 and 2).

The SGOT values were significantly higher in the ascorbic acid group than in the control $(p<0.001)$ and U74389G $(p<0.001)$ groups (Table III).

Finally, there was no statistically significant difference between the two reperfusion times $(60 \mathrm{~min} v s .120 \mathrm{~min}$ ) for all variables in the control and ascorbic acid groups [only the $\gamma$-GT value $(p=0.005)$ was significantly different]. There was a statistically significant difference between the two reperfusion times (60 $\mathrm{min} v s .120 \mathrm{~min})$ for TNF- $\alpha$ $(p=0.0005)$, SGOT $(p=0.022)$, SGPT $(p=0.022), \quad \gamma$-GT $(p=0.006)$, and creatinine $(p=0.035)$ (Table IV).

In the control group, renal damage was exacerbated in all the estimated variables. A statistically significant difference was found regarding renal damage among groups $\mathrm{E}$ and $\mathrm{F}$ compared with the control and ascorbic acid groups.

\section{Discussion}

The complex cascade of ischemia, reperfusion, and inflammatory processes in kidney cells could result in entirely opposite outcomes, namely injury or recovery. IRI is an inflammatory process involving various factors and molecules that may contribute to cellular dysfunction. Renal endothelial and tubular epithelial cells are predisposed to IRI (25-28).

Following ischemia, oxidant attack stimulates cytokine or chemokine upregulation, activating inflammatory cells to mediate injury via TNF- $\alpha$ and IFN- $\gamma$ expression $(29,30)$.

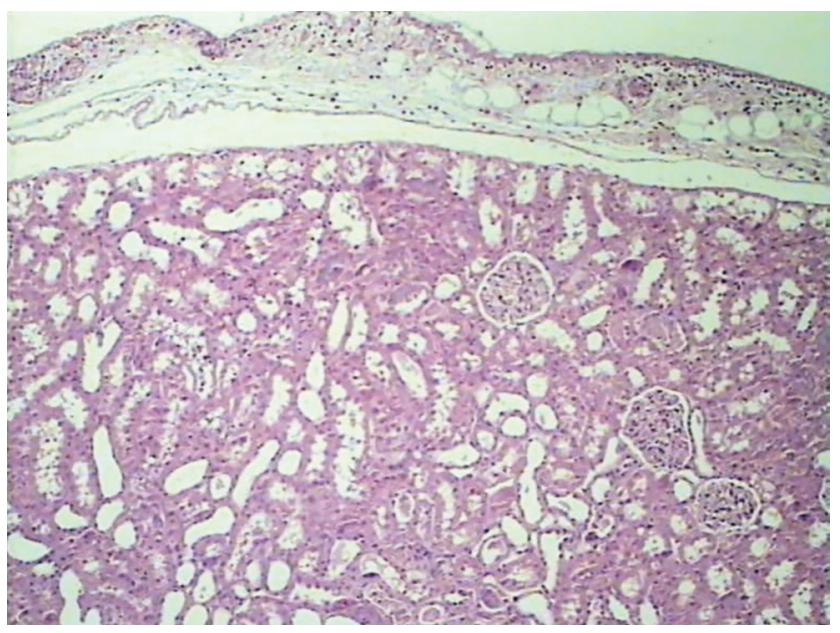

Figure 8. Few degenerated renal tubules with central distribution (250x). Group F [kidney ischemia (30 min), U-74389G intravenous injection, and reperfusion for $120 \mathrm{~min}$ ].

Table II. Comparison between groups at 60 min reperfusion.

\begin{tabular}{lcccr}
\hline & Control & Ascorbic & U74389G & $p$-Value \\
\hline MDA $(\mu \mathrm{M})$ & $4.82 \pm 2.00$ & $3.19 \pm 0.56$ & $4.32 \pm 1.58$ & 0.085 \\
60 rep & & & & \\
TNF- $\alpha$ 60 rep & $861.75 \pm 442.08$ & $734.52 \pm 248.99$ & $911.76 \pm 384.51$ & 0.546 \\
SGOT 60 rep & $270.60 \pm 89.37^{\dagger}$ & $395.50 \pm 131.66$ & $271.40 \pm 36.83^{\dagger}$ & 0.008 \\
SGPT 60 rep & $88.00 \pm 36.29^{*}$ & $79.60 \pm 22.12$ & $85.50 \pm 31.42$ & 0.820 \\
ALP 60 rep & $99.40 \pm 27.84^{* *}$ & $92.20 \pm 19.12^{* *}$ & $155.00 \pm 43.26$ & $<0.001$ \\
Y-GT 60 rep & $1.30 \pm 0.48^{* \dagger}$ & $3.80 \pm 3.22$ & $4.60 \pm 3.31$ & 0.027 \\
Cre 60 rep & $0.72 \pm 0.06^{\dagger \dagger}$ & $0.86 \pm 0.08$ & $0.65 \pm 0.10^{\dagger \dagger}$ & $<0.001$ \\
\hline
\end{tabular}

${ }^{*} p<0.05 v s . \mathrm{U} 74389 \mathrm{G},{ }^{*} p<<0.005 v s . \mathrm{U} 74389 \mathrm{G} ;{ }^{\dagger} p<0.05 v s$. Ascorbic, $\dagger p<0.005 v s$. Ascorbic.

Table III. Comparison between groups at 120 min reperfusion.

\begin{tabular}{lcccc}
\hline & Control & Ascorbic & U74389G & $p$-Value \\
\hline $\begin{array}{l}\text { MDA }(\mu \mathrm{M}) \\
\text { 120 rep }\end{array}$ & $4.27 \pm 2.03$ & $2.93 \pm 0.40^{*}$ & $4.48 \pm 1.11$ & 0.034 \\
TNF- $\alpha$ & $892.11 \pm 314.04 * *$ & $792.46 \pm 148.05^{* *}$ & $1970.64 \pm 43.57$ & $<0.001$ \\
120 rep & & & & \\
SGOT & $323.50 \pm 88.78 \dagger$ & $459.10 \pm 140.92$ & $414.30 \pm 115.51$ & 0.045 \\
120 rep & & & & \\
SGPT & $90.30 \pm 34.01 *$ & $67.20 \pm 14.34 * *$ & $130.80 \pm 48.03$ & 0.001 \\
120 rep & & & & \\
ALP & $81.50 \pm 21.54 * *$ & $88.70 \pm 15.44 * *$ & $156.20 \pm 43.26$ & $<0.001$ \\
120 rep & & & & \\
$\gamma$-GT & $1.30 \pm 0.48^{\dagger \dagger}$ & $7.40 \pm 1.58$ & $1.10 \pm 1.20^{\dagger \dagger}$ & $<0.001$ \\
120 rep & & & & \\
Cre 120 rep & $0.80 \pm 0.12 * *$ & $0.85 \pm 0.23 * *$ & $0.54 \pm 0.12$ & $<0.001$ \\
\hline
\end{tabular}

${ }^{*} p<0.05 v s . \mathrm{U} 74389 \mathrm{G},{ }^{*} * p<0.005 v s . \mathrm{U} 74389 \mathrm{G} ;{ }^{\dagger} p<0.05 v s$. Ascorbic, $\dagger p<0.005$ vs. Ascorbic. 
Table IV. Analysis of time intervals for reperfusion per group.

\begin{tabular}{|c|c|c|c|c|c|c|}
\hline & Control & $p$-Value & Ascorbic & $p$-Value & U74389G & $p$-Value \\
\hline \multicolumn{7}{|c|}{$\operatorname{MDA}(\mu \mathrm{M})$} \\
\hline 60 rep & $4.82 \pm 2.00$ & \multirow[t]{2}{*}{0.545} & $3.19 \pm 0.56$ & \multirow[t]{2}{*}{0.260} & $4.32 \pm 1.58$ & \multirow[t]{2}{*}{0.792} \\
\hline 120 rep & $4.27 \pm 2.03$ & & $2.93 \pm 0.40$ & & $4.48 \pm 1.11$ & \\
\hline \multicolumn{7}{|l|}{$\mathrm{TNF}-\alpha$} \\
\hline 60 rep & $861.75 \pm 442.08$ & \multirow[t]{2}{*}{0.861} & $734.52 \pm 248.99$ & \multirow[t]{2}{*}{0.535} & $911.76 \pm 384.51$ & \multirow[t]{2}{*}{$<0.001$} \\
\hline 120 rep & $892.11 \pm 314.04$ & & $792.46 \pm 148.05$ & & $1970.64 \pm 43.57$ & \\
\hline \multicolumn{7}{|l|}{ SGOT } \\
\hline 60 rep & $270.60 \pm 89.37$ & \multirow[t]{2}{*}{0.201} & $395.50 \pm 131.66$ & \multirow[t]{2}{*}{0.311} & $271.40 \pm 36.83$ & \multirow[t]{2}{*}{0.022} \\
\hline 120 rep & $323.50 \pm 88.78$ & & $459.10 \pm 140.92$ & & $414.30 \pm 115.51$ & \\
\hline \multicolumn{7}{|l|}{ SGPT } \\
\hline 60 rep & $88.00 \pm 36.29$ & \multirow[t]{2}{*}{0.885} & $79.60 \pm 22.12$ & \multirow[t]{2}{*}{0.154} & $85.50 \pm 31.42$ & \multirow[t]{2}{*}{0.022} \\
\hline 120 rep & $90.30 \pm 34.01$ & & $67.20 \pm 14.34$ & & $130.80 \pm 48.03$ & \\
\hline \multicolumn{7}{|l|}{ ALP } \\
\hline 60 rep & $99.40 \pm 27.84$ & \multirow[t]{2}{*}{0.125} & $92.20 \pm 19.12$ & \multirow[t]{2}{*}{0.658} & $155.00 \pm 43.26$ & \multirow[t]{2}{*}{0.951} \\
\hline 120 rep & $81.50 \pm 21.54$ & & $88.70 \pm 15.44$ & & $156.20 \pm 43.26$ & \\
\hline \multicolumn{7}{|l|}{$\gamma$-GT } \\
\hline 60 rep & $1.30 \pm 0.48$ & \multirow[t]{2}{*}{1.000} & $3.80 \pm 3.22$ & \multirow[t]{2}{*}{0.005} & $4.60 \pm 3.31$ & \multirow[t]{2}{*}{0.006} \\
\hline 120 rep & $1.30 \pm 0.48$ & & $7.40 \pm 1.58$ & & $1.10 \pm 1.20$ & \\
\hline \multicolumn{7}{|l|}{ Cre } \\
\hline 60 rep & $0.72 \pm 0.06$ & \multirow[t]{2}{*}{0.175} & $0.86 \pm 0.08$ & \multirow[t]{2}{*}{0.898} & $0.65 \pm 0.10$ & \multirow[t]{2}{*}{0.035} \\
\hline $120 \mathrm{rep}$ & $0.80 \pm 0.12$ & & $0.85 \pm 0.23$ & & $0.54 \pm 0.12$ & \\
\hline
\end{tabular}

Bold values indicate statistical significance.

Currently, no specific treatments exist to reduce IRI, as most of the pathogenetic mechanisms involved have not been thoroughly elucidated. The most prominent mechanisms are alterations in hemodynamics and in the microvasculature of the renal tubules. Other mechanisms include alterations in cellula metabolism and gene expression. In addition, IRI in clinical practice is usually multi-factorial, with concurrent components such as ischemia, nephrotoxicity, and sepsis (31).

It has been indicated that nuclear factor- $\mathrm{kB}(\mathrm{NF}-\mathrm{kB})$ is instrumental in IRI pathogenesis (32-36). NF- $\mathrm{kB}$ is principally responsible for producing reactive oxygen species (ROS), chemokines, and cytokines and control pro- or anti-apoptotic signaling, eventually crucial for IRI generation $(32,34,35)$. NF-kB acts as a factor of transcription in tubular epithelial and inflammatory cells, bridging the equilibrium between cell death signaling pathways and inflammatory processes. In addition, it was shown in a mouse model of renal IRI that NF$\mathrm{KB}$ activation of renal tubular epithelial cells impaired tubular injury and accentuated the inflammatory process (36). More research may lead to IRI treatment centered on NF-kB (37).

Efforts have been made to prevent IRI that impairs renal graft function after kidney transplantation with the use of calcium-channel blockers and L-arginine.

Other substances that have been administered and proven to be beneficial in diminishing acute kidney damage in experimental models are dopamine, fenoldopam, and atrial natriuretic peptide (1). Many other antioxidants have been successfully used in experimental models but only few have been tested on humans undergoing kidney transplantation. It has been shown that pretreatment with specific antioxidants could ameliorate the damage of IRI in kidney transplantation.

Lazaroids have been suggested to have a therapeutic effect on IRI in various organs $(7,8)$. Using our current experimental model, we examined the antioxidant protective function of lazaroids and ascorbic acid against IRI.

$\mathrm{N}$-acetylcysteine and L-arginine are also potential therapeutic factors. Other auspicious results have been obtained in experimental models with vitamin E peroxinitrite, nitrosithiols, ligustrazine, allopurinol, and folate. However, scarce clinical transplantation-related studies have been conducted using few of these agents. We are far from determining whether pretreatment with these antioxidants can ameliorate renal function in kidney transplantation. Other researchers have reported failure in administrating antioxidants to pathologies where the pivotal role of ROS was considered the principal pathogenetic mechanism, such as in pancreatic IRI (6).

A study by Koul et al. that employed a rat model concluded that ascorbic acid protects against IRinduced acute kidney injury (38). Similar studies to ours have shown the protective role of vitamins $\mathrm{C}$ and $\mathrm{E}$ in attenuating oxidative stress following renal ischemia in a rat model (39), probably by radical scavenging and expressing antioxidant properties (40). Different parameters were evaluated but similar results to our study were shown by Ergin et al. concerning renal microcirculation after IRI (41). 
One of the strengths of our study is that we attempted a more holistic approach to examine the potentially beneficial effect of both molecules (ascorbic acid and U-74389G) instead of using a fragmental evaluation of some parameters. In contrast, a limitation of our study is that we did not evaluate IRI for $24 \mathrm{~h}$. Moreover, experimental studies in larger mammals than rats are anticipated.

Numerous issues still remain unanswered, such as the different functions of inflammatory cells. According to experimental studies, targeting inflammatory pathways has a protective action in rodents; conversely, clinical studies have shown that targeting the same pathways in humans has no therapeutic effect. Moreover, bridging the underlying mechanisms of acute rejection and ischemic graft injury with intervention with novel therapeutic agents would be of paramount importance $(42,43)$.

The results of our study emphasize the effect of the inherent immune response on the pathogenesis of IRI, leading to potential therapeutic options. However, based on our search, these potentially therapeutic strategies have not been incorporated into clinical practice for IRI evaluation.

Equally, U-74389G and ascorbic acid that were found to be protective in our experimental rat model, should be applied to clinical scenarios.

\section{Conclusion}

In conclusion, this study, which consolidated statistically significant histopathological results $(p<0.01)$ in renal tubular degeneration or necrosis and found a substantial decrease in MDA and TNF- $\alpha$ levels, indicates the superiority of ascorbic acid at $120 \mathrm{~min}$ of reperfusion to lazaroid U-74389G in repairing renal damage from IRI. In contrast, there was no significant difference in MDA and TNF- $\alpha$ among the groups at $60 \mathrm{~min}$ of reperfusion.

\section{Conflicts of Interest}

The Authors declare no conflicts of interest regarding this study.

\section{Authors' Contributions}

AEP, KZ, AC, DC: conception and design of the study; KZ, VK, DC, AC, KP, MS: acquisition of data, drafting the article; AG: statistical analysis; TP, IS: histological study, analysis of histological scores; DC, MS, AEP: drafting the article, revising it critically for important intellectual content; AEP, EF, GZ, DC: final approval of the version to be submitted.

\section{Acknowledgements}

This research did not receive any specific grant from funding agencies in the public, commercial, or not-for-profit sectors but supported as experiment (consumables, animals, and staff, from ELPEN Pharma).

\section{References}

1 Ponticelli C: Ischaemia-reperfusion injury: a major protagonist in kidney transplantation. Nephrol Dial Transplant 29(6): 11341140, 2014. PMID: 24335382. DOI: $10.1093 / \mathrm{ndt} / \mathrm{gft} 488$

2 Pefanis A, Ierino FL, Murphy JM and Cowan PJ: Regulated necrosis in kidney ischemia-reperfusion injury. Kidney Int 96(2): 291-301, 2019. PMID: 31005270. DOI: 10.1016/j.kint.2019.02.009

3 Bonventre JV and Yang L: Cellular pathophysiology of ischemic acute kidney injury. J Clin Invest 121(11): 4210-4221, 2011. PMID: 22045571. DOI: 10.1172/JCI45161

4 Ishimaru K, Mitsuoka H, Unno N, Inuzuka K, Nakamura S and Schmid-Schönbein GW: Pancreatic proteases and inflammatory mediators in peritoneal fluid during splanchnic arterial occlusion and reperfusion. Shock 22(5): 467-471, 2004 PMID: 15489640. DOI: 10.1097/01.shk.0000142253.31006.8c

5 Leindler L, Morschl E, László F, Mándi Y, Takács T, Jármai K and Farkas G: Importance of cytokines, nitric oxide, and apoptosis in the pathological process of necrotizing pancreatitis in rats. Pancreas 29(2): 157-161, 2004. PMID: 15257108. DOI: 10.1097/00006676-200408000-00011

6 Chrysikos DT, Sergentanis TN, Zagouri F, Psaltopoulou T, Flessas I, Agrogiannis G, Alexakis N, Bramis I, Patsouri EE, Patsouris ES, Korontzi M, Katsarou A, Zografos GC and Papalois AE: The effect of U-74389G on pancreas ischemiareperfusion injury in a swine model. J Surg Res 187(2): 450-457, 2014. PMID: 24332939. DOI: 10.1016/j.jss.2013.11.1082

7 Korontzi MI, Theodoropoulos G, Agrogiannis G, Flessas I, Chrysikos D, Gioxari A, Sergentanis TN, Patsouris E, Zografos GC and Papalois A: Lazaroid U-74389G in liver ischemiareperfusion injury: A swine model. Exp Ther Med 18(1): 230236, 2019. PMID: 31258658. DOI: 10.3892/etm.2019.7561

8 Flessas I, Bramis I, Menenakos E, Toutouzas K, Agrogiannis G, Patsouris E, Nonni A, Chrysikos D, Korontzi M, Gioxari A, Zografos G and Papalois A: Effects of lazaroid U-74389G on intestinal ischemia and reperfusion injury in porcine experimental model. Int J Surg 13: 42-48, 2015. PMID: 25438077. DOI: 10.1016/j.ijsu.2014.11.030

9 Niederau C, Schulz HU and Klonowski H: Lazaroids protect isolated rat pancreatic acinar cells against damage induced by free radicals. Pancreas 11(2): 107-121, 1995. PMID: 7479666. DOI: 10.1097/00006676-199508000-00001

10 Schulz HU, Hoenl H, Schrader T, Kropf S, Halangk W, Ochmann C, Matthias R, Letko G, Roessner A, Lippert H and Niederau C: Randomized, placebo-controlled trial of lazaroid effects on severe acute pancreatitis in rats. Crit Care Med 29(4): 861-869, 2001. PMID: 1137348. DOI: 10.1097/00003246-200104000-00035

11 Braughler JM, Pregenzer JF, Chase RL, Duncan LA, Jacobsen EJ and McCall JM: Novel 21-amino steroids as potent inhibitors of iron-dependent lipid peroxidation. J Biol Chem 262(22): 10438-10440, 1987. PMID: 3611075.

12 Clark WM, Hazel JS and Coull BM: Lazaroids: CNS pharmacology and current research. Drugs 50(6): 971-983, 1995. PMID:8612475. DOI: 10.2165/00003495-199550060-00005

13 Tsaroucha AK, Papalois A, Vernadakis S, Adamopoulos S, Papadopoulos K, Lambropoulou M, Constadinidis T, Kyriazi A, Papadopoulos N and Simopoulos C: The effect of U-74389G on liver recovery after acute liver ischemia-reperfusion injury in a swine model. J Surg Res 151(1): 10-14, 2009. PMID: 18468628. DOI: $10.1016 /$ j.jss.2008.01.024 
14 Hillinger S, Schmid RA, Stammberger U, Boehler A, Schöb $\mathrm{OM}$, Zollinger A and Weder W: Donor and recipient treatment with the Lazaroid U-74006F do not improve post-transplant lung function in swine. Eur J Cardiothorac Surg 15(4): 475-480, 1999. PMID: 1037112. DOI: 10.1016/s1010-7940(99)00022-6

15 Cosenza CA, Cramer DV, Cunneen SA, Tuso PJ, Wang HK and Makowka L: Protective effect of the lazaroid U74006F in cold ischaemia-reperfusion injury of the liver. Hepatology 19(2): 418425, 1994. PMID: 8294099.

16 Andreadou I, Poussios D, Papalois A, Gavalakis N, Aroni K, Gazouli M, Gorgoulis VG and Fotiadis C: Effect of U74389G (21-lazaroid) on intestinal recovery after acute mesenteric ischaemia and reperfusion in rats. In Vivo 17(5): 463468, 2003. PMID: 14598610.

17 Todo S, Hamada N, Zhu Y, Zhang S, Subbotin V, Nemoto A, Takeyoshi I and Starzl TE: Lazaroid U-74389G for 48-hour canine liver preservation. Transplantation 61(2): 189-194, 1996. PMID: 8600621. DOI: 10.1097/00007890-199601270-00004

18 Rhoden EL, Pereira-Lima L, Kalil AN, Lucas ML, Mauri M, Menti E, Rhoden CR, Pereira-Lima J, Zettler CG and BellóKlein A: Effects of ischaemia and reperfusion on oxidative stress in hepatic cirrhosis induced by carbon tetrachloride in rats. Kobe J Med Sci 46(4): 171-180, 2000. PMID: 11354928.

19 Leventis I, Andreadou I, Papalois A, Sfiniadakis I, Gorgoulis VG, Korkolis DP, Hadjipavlou-Litina D, Kourounakis PN and Fotiadis C: A novel antioxidant non-steroidal anti-inflammatory agent protects rat liver against ischaemia-reperfusion injury. In Vivo 18(2): 161-169, 2004. PMID: 15113043.

20 Tanaka H, Zhu Y, Zhang S, Ishizaki N, Jin MB, Azuma T, Lee $\mathrm{R}$, Starzl TE and Todo S: Lazaroid U-74500A for warm ischaemia and reperfusion injury of the canine small intestine. J Am Coll Surg 184(4): 389-396, 1997. PMID: 9100685.

21 Zumbabo M, Dominguez-Diez A, Hernandez JR, Díaz JM, Palomar R, García-Plaza G, Navarro D and Boada LD: Evaluation of the potential protective effect of 21-aminosteroid U-74389G on liver injury induced and prolonged partial hepatic ischaemia reperfusion in rats. Pharmacol Toxicol 93(5): 238-243, 2003. PMID: 14629736. DOI: 10.1046/j.1600-0773.2003. pto930507.x

22 Iwanami K, Takeyoshi I, Ohwada S, Kobayashi J, Kawashima Y, Aiba M, Matsumoto K and Morishita Y: The effect of lazaroid U-74389G on extended liver resection with ischaemia in dogs. Surgery 126(5): 908-917, 1999. PMID: 10568191.

23 Ishizaki N, Zhu Y, Zhang S, Nemoto A, Kobayashi Y, Subbotin $\mathrm{V}$, Starzl TE and Todo S: Comparison of various lazaroids compounds for protection against ischemic liver injury. Transplantation 63(2): 202-208, 1997. PMID: 9020318. DOI: 10.1097/00007890-199701270-00005

24 Abdullah M, Jamil RT and Attia FN: Vitamin C (Ascorbic Acid). StatPearls (Internet). Treasure Island (FL): StatPearls Publishing, 2019-2020.

25 Zhang ZX, Wang S, Huang X, Min WP, Sun H, Liu W, Garcia $\mathrm{B}$ and Jevnikar AM: NK cells induce apoptosis in tubular epithelial cells and contribute to renal ischemia-reperfusion injury. J Immunol 181(11): 7489-7498, 2008. PMID: 19017938. DOI: 10.4049/jimmunol.181.11.7489

26 Bonventre JV: Dedifferentiation and proliferation of surviving epithelial cells in acute renal failure. J Am Soc Nephrol 14(Suppl. 1): S55-S61, 2003. PMID: 12761240. DOI: 10.1097/ 01.asn.0000067652.51441.21
27 Molitoris BA and Sutton TA: Endothelial injury and dysfunction: role in the extension phase of acute renal failure. Kidney Int 66(2): 496-499, 2004. PMID: 15253696. DOI: 10.1111/j.15231755.2004.761_5.x

28 Boros P and Bromberg JS: New cellular and molecular immune pathways in ischemia/reperfusion injury. Am J Transplant 6(4): 652-658, 2006. PMID: 16539620. DOI: 10.1111/j.16006143.2005.01228.x

29 Toledo-Pereyra L H, Lopez-Neblina F and Toledo AH: Reactive oxygen species and molecular biology of ischemia/reperfusion. Ann Transplant 9(1): 81-83, 2004. PMID: 15478900.

30 Millar T M., Phan V and Tibbles LA: ROS generation in endothelial hypoxia and reoxygenation stimulates MAP kinase signaling and kinase-dependent neutrophil recruitment. Free Radic Biol Med 42(8): 1165-1177, 2007. PMID: 17382198. DOI: $10.1016 /$ j.freeradbiomed.2007.01.015

31 Devarajan P: Update on mechanisms of ischemic acute kidney injury. J Am Soc Nephrol 17(6): 1503-1520, 2006. PMID: 16707563. DOI: 10.1681/ASN.2006010017

32 Gupta S, Verfaillie C, Chmielewski D, Kim Y and Rosenberg ME: A role for extrarenal cells in the regeneration following acute renal failure. Kidney Int 62(4): 1285-1290, 2002. PMID: 12234298. DOI: 10.1111/j.1523-1755.2002.kid569.x

33 Poulsom R, Alison MR, Cook T, Jeffery R, Ryan E, Forbes SJ, Hunt T, Wyles $\mathrm{S}$ and Wright NA: Bone marrow stem cells contribute to healing of the kidney. J Am Soc Nephrol 14(Suppl 1): S48-S54, 2003. PMID: 12761239. DOI: 10.1097/01.asn. 0000068162.02174 .29

34 Lin F, Cordes K, Li L, Hood L, Couser WG, Shankland SJ and Igarashi P: Hematopoietic stem cells contribute to the regeneration of renal tubules after renal ischemia-reperfusion injury in mice. J Am Soc Nephrol 14(5): 1188-1199, 2003. PMID: 12707389. DOI: 10.1097/01.asn.0000061595.28546.a0

35 Kale S, Karihaloo A, Clark PR, Kashgarian M, Krause DS and Cantley LG: Bone marrow stem cells contribute to repair of the ischemically injured renal tubule. J Clin Invest 112(1): 42-49, 2003. PMID: 12824456 . DOI: $10.1172 / J C I 17856$

36 Morigi M, Imberti B, Zoja C, Corna D, Tomasoni S, Abbate M, Rottoli D, Angioletti S, Benigni A, Perico N, Alison M and Remuzzi G: Mesenchymal stem cells are renotropic, helping to repair the kidney and improve function in acute renal failure. $\mathrm{J}$ Am Soc Nephrol 15(7): 1794-1804, 2004. PMID: 15213267. DOI: 10.1097/01.asn.0000128974.07460.34

37 Kezić A, Stajic N and Thaiss F: Innate immune response in kidney ischemia/reperfusion injury: potential target for therapy. J Immunol Res 2017: 6305439, 2017. PMID: 28676864. DOI: $10.1155 / 2017 / 6305439$

38 Koul V, Kaur A and Singh AP: Investigation of the role of nitric oxide/soluble guanylyl cyclase pathway in ascorbic acidmediated protection against acute kidney injury in rats. Mol Cell Biochem 406(1-2): 1-7, 2015. PMID: 26142728. DOI: 10.1007/ s11010-015-2392-4

39 Sirmali R, Armağan A, Öktem F, Uz E, Kirbas A, Dönmezs S, Yilmaz HR, Silay MS and Sirmali M: Protective effects of erdosteine, vitamin $\mathrm{E}$, and vitamin $\mathrm{C}$ on renal injury induced by the ischemia-reperfusion of the hind limbs in rats. Turk J Med Sci 45(1): 33-37, 2015. PMID: 25790527. DOI: 10.3906/sag1310-38

40 Korkmaz A and Kolankaya D: The protective effects of ascorbic acid against renal ischemia-reperfusion injury in male rats. Ren 
Fail 31(1): 36-43, 2009. PMID: 19142808. DOI: 10.1080/ 08860220802546271

41 Ergin B, Zuurbier CJ, Bezemer R, Kandil A, Almac E, Demirci $\mathrm{C}$ and Ince $\mathrm{C}$ : Ascorbic acid improves renal microcirculatory oxygenation in a rat model of renal I/R injury. J Transl Int Med 3(3): 116-125, 2015. PMID: 27847899. DOI: 10.1515/jtim-20150011

42 Situmorang GR and Sheerin NS: Ischaemia reperfusion injury: mechanisms of progression to chronic graft dysfunction. Pediatr Nephrol 34(6): 951-963, 2019. PMID: 29603016. DOI: 10.1007/s00467-018-3940-4
43 Nieuwenhuijs-Moeke GJ, Pischke SE, Berger SP, Sanders JSF, Pol RA, Struys MMRF, Ploeg RJ and Leuvenink HGD: Ischemia and reperfusion injury in kidney transplantation: relevant mechanisms in injury and repair. J Clin Med 9(1): pii: E253, 2020. PMID: 31963521. DOI: $10.3390 /$ jcm 9010253

Received April 26, 2020

Revised June 2, 2020

Accepted June 5, 2020 